\title{
Experimental Analysis of Xie and Kuek's Traffic Model with Handoff Scheme in Wireless Networks
}

\author{
BISWAJIT BHOWMIK $^{1}$, POOJA $^{2}$, NUPUR THAKUR ${ }^{2}$, PIYALI SARKAR $^{2}$ \\ ${ }^{1}$ Member of IEEE, IACSIT, IAENG, PASS, IAOE, IAS, and UACEE, \\ Department of Computer Science \& Engineering, Indian Institute of Technology Guwahati, 781039, India. \\ Email: b.bhowmik@iitg.ernet.in, biswajitbhowmik@gmail.com \\ ${ }^{2}$ Department of Computer Science \& Engineering, Bengal College of Engineering and Technology, \\ Durgapur, 713212, India \\ E-mail: pooja.cse2308@gmail.com,nupurcse07@gmail.com,piyali.doanju@gmail.com
}

\begin{abstract}
Mobility becomes a distinct feature for a wireless mobile cellular system. For the traffic which is non stationary and is away from the base station, the chances of a call to be handed off are increased. In urban mobile cellular systems, especially when the cell size becomes relatively small, the Handoff procedure has a significant impact on system performance. Blocking probability of originating calls and the forced termination probability of ongoing calls are the primary criteria for indicating this performance. In this paper, we report our recent work on closed form solutions to the blocking probability followed by dropping probability in wireless cellular networks with Handoff . First, we develop a performance model EATM of a cell in a wireless network where the effect of Handoff Arrivals arrivals and the use of guard channels are included. Then we simulate the Xie and Kuek's Traffic Model with exploiting our model.
\end{abstract}

Index Terms - Mobile Station, Arrival Rate, Outgoing Rate, Blocking Probability, CBR.

\section{Introduction}

The rapid growth in the demand for mobile communications has led to an intense research effort to achieve an efficient use of the scarce spectrum or channel allocated for cellular communications. Traffics (request and demand for service) in the wireless networks are ever increasing and are expected to be extremely non stationary [1][2]. The channel associated with the current connection serviced by a Base Stations (BS) is changed while a call is in progress. The Non Stationary Calls simply called Mobile Stations (MSs) are when away from the current BS (also called Mobile Ter minal, (MT)) the chances of Handoff [3] are increased. It is often initiated either by crossing a cell boundary or by deterioration in quality of the signal in the current channel. The existing call is then changed to a new nearest $B S$. Continuous service is achieved by supporting Handoff mechanism from one cell to the next adjacent cell as the MSs move through the coverage area is shown in Figure 1 below. We assume that every cell in the system is of the same size and has the same fixed number of channels. There are no guarded channels for Handoff calls in any cell, i.e., both new and Handoff calls have access to all the channels. Each MS is associated with a call at any given time. If a new call that is generated in a cell cannot find an idle channel in that cell, the call is discarded (blocked) immediately. An Handoff algorithm determines the dynamics of the MS which moves through the network. Therefore, Handoffs in a mobile cellular communications environment have become an increasingly important issue accommodating an increasingly large demand for services with simultaneous reduced cell sizes $[3][4][5][6][7][8][9][10]$. 


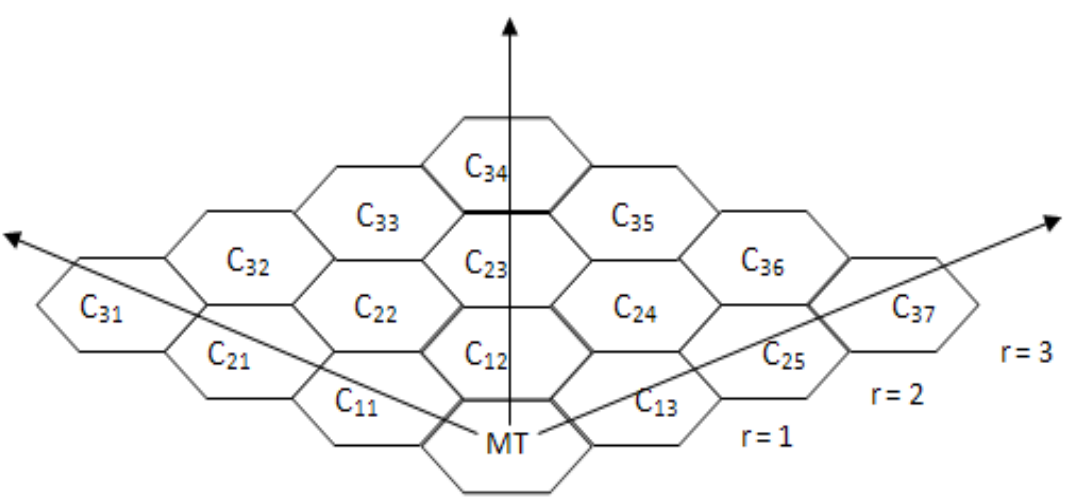

Figure 1. Same Column and Non-column Cellular Configuration for $r=3$

In urban mobile cellular radio systems, especially when the cell size becomes relatively small, the Handoff mechanism has a significant impact on primary system performance criteria: Blocking probability of originating calls $\left(B_{O}\right)$, Blocking probability of Handoff calls $\left(B_{H}\right)$, and the forced termination probability of ongoing calls [3][8]. Before analyzing these performance criteria, it is important to establish a traffic model. In this paper we propose to modelling, implement and simulate the Xie and Kuek's Traffic Model [3] with Handoff behavior for mobile network. A simulation model EATM (Experimental Analysis of Traffic Model) with priority Handoff scheme is developed to investigate the Handoff performances. Simulation results show that measurement of blocking probabilities for both originating and Handoff calls is an impressive achievement of the model. In addition to this, the proposed model can increase Call Blocking Rate (CBR) as derived in [1][8][11][12] and shown in Equation (11) of Handoff calls.

\section{Proposed Work}

Every cell in cellular network architecture (shown in Figure 1) is served by an underlying BS that is $M T$. $B S s$ are connected together by using a wireless network. Figure 2(a) shows the fact that each hexagonal cell A, D, $\mathrm{Q}, \mathrm{P}, \mathrm{X}, \mathrm{Y}$, and $\mathrm{Z}$ are nothing but each MT . MSs generally move in the coverage area (each hexagon) similar to Figure 2 [13][14][15] and Table I [8] and when moving from a cell to another cell, Handoff occurs [3]. Movements may be made away from and/or towards the $M T$. However, movements away from the current $M T$ is primarily responsible for Handoff to be taken place. For the time being suppose cell A in Figure 2(a) is our current BS. However, one-third of the coverage area of this BS is considered in this paper and equivalent to Figure 1.

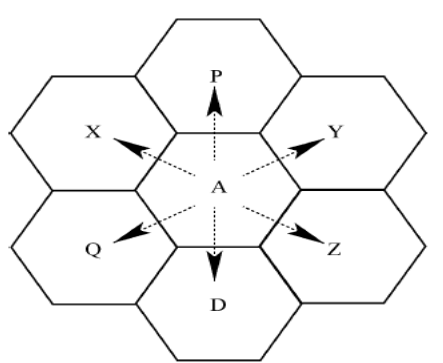

(a)

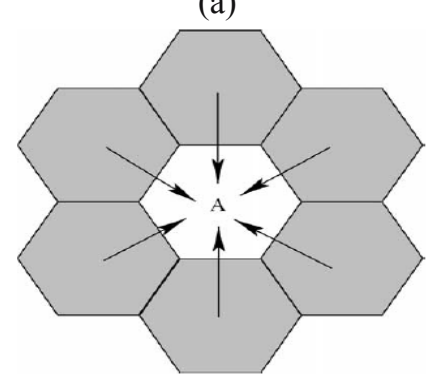

(b)

Figure 2. Mobility of Mobile Stations (MSs)

When MSs move irrespective of the direction of movements in the cell of the current servicing $B S$ then the following two cases and their corresponding sub cases [15] may arise: First, Call Acceptance - (a) A successful Handoff completion to the target cell, (b) New call arrival in the target cell, and (c) Active mobile terminal increases its resource demands. Second, Call Rejection - (a) A successful Handoff completion from the target cell. (b) Call termination in the target cell and (c) Active mobile terminal decreases its resource demands.

The current researches on Handoff mainly involve following two issues: (1) How does the Handoff process affect performance of wireless cellular system; (2) How do we design Handoff scheme so that channel resources are used efficiently and quality of service (QoS) is still guaranteed.

Recently, many analytical and simulation models have characterized the Handoff problems. Our approach provides high precise location and tracking of MTs by exploiting advanced traffic models. Some of these we have studied it in [1][7][8]. 
Table I: Generated Handoff Approaches

\begin{tabular}{|c|c|c|c|c|c|c|}
\hline Approach & \multicolumn{2}{|l|}{ Movement of MSs w.r.t MT } & \multicolumn{2}{l|}{ Adjacent Level } & \multicolumn{2}{l|}{ Position of Cells Column } \\
\hline \multirow{3}{*}{ I } & Towards & Away from & Upper & Lower & Same Column & Not Same Column \\
\cline { 2 - 7 } & $\mathrm{N}$ & $\mathrm{Y}$ & $\mathrm{Y}$ & $\mathrm{N}$ & $\mathrm{Y}$ & $\mathrm{N}$ \\
\hline \multirow{2}{*}{ II } & $\mathrm{Y}$ & $\mathrm{N}$ & $\mathrm{N}$ & $\mathrm{Y}$ & $\mathrm{Y}$ & $\mathrm{N}$ \\
\cline { 2 - 7 } & $\mathrm{Y}$ & $\mathrm{Y}$ & $\mathrm{Y}$ & $\mathrm{N}$ & $\mathrm{Y}$ & $\mathrm{N}$ \\
\hline \multirow{2}{*}{ III } & $\mathrm{N}$ & $\mathrm{Y}$ & $\mathrm{Y}$ & $\mathrm{N}$ & $\mathrm{N}$ & $\mathrm{Y}$ \\
\cline { 2 - 7 } & $\mathrm{Y}$ & $\mathrm{N}$ & $\mathrm{N}$ & $\mathrm{Y}$ & $\mathrm{Y}$ & $\mathrm{Y}$ \\
\hline \multirow{2}{*}{$\mathrm{IV}$} & $\mathrm{N}$ & $\mathrm{Y}$ & $\mathrm{Y}$ & $\mathrm{N}$ & $\mathrm{N}$ & $\mathrm{N}$ \\
\cline { 2 - 7 } & $\mathrm{Y}$ & $\mathrm{N}$ & $\mathrm{N}$ & $\mathrm{Y}$ & $\mathrm{N}$ & $\mathrm{Y}$ \\
\hline
\end{tabular}

Here we have extended our work [16] with Xie and Kuek's Traffic Model [3]. Our approach EATM Model takes more advantages over previous models described in [1][7][8]. Major functionalities of the proposed model in this paper are organized in as follows:

First, we present an expression to Determine Arrival Rate $(\lambda o)$ of the calls followed by the expression of their Departure Rate $(\mu)$ Determination. Next, we choose a model through Traffic Model Selection. Next, we are going to implement a Priority Handoff Scheme. And last we have determined Call Blocking Rate of both originating calls and Handoff calls.

\subsection{Determination of Arrival Rate}

Number of MSs (also called Traffic Density [17]) varies location to location. And this location on the contrary affects arrival rate $\lambda_{0}$ of originating calls from $M S$ s to nearest BS (MT). Likewise number of BSs varies. Assuming distance D [18][19] between two base stations is $1 \mathrm{~km}, \lambda o$ [3] has been determined in $S 2 B P Q$ model [16] as:

$\lambda o=\frac{\text { TotalNumberof Subscriber }(\mathrm{S}) \text { in thatRegion }}{\text { TotalNumberof } \operatorname{MTs}(\mathrm{X})}$

\subsection{Determination of Departure Rate}

The departure rate $\mu$ (say, number of mobile stations get serviced in unit time) should be at least equal to arrival rate $\lambda o$ such that waiting for getting service becomes zero. Although in reality $\mu$ is much larger than $\lambda o$. Exploiting Poison Distribution [17], with the traffic intensity factor $\rho$ (defined as $\lambda o / \mu$ ) lies between 0 and 1, departure rate $\mu$ has been established in S2BPQ Model [16] as:

$$
0 \leq \lambda o \leq \mu
$$

\subsection{Selection of Traffic Model}

Every cell in cellular network architecture ( shown in Figure 1) is served by an underlying BS . Establishment of a traffic model, in cellular system, is more imperative before analyzing the performance of the system [8][16]. Several traffic models [3][20] as well as different schemes [21][22][15][10] have been established on basis of making different assumptions about user mobility. One of them is the Expected Rate of Handoff $\left(\lambda_{H}\right)$.

For our purpose Xie and Kuek's Traffic Model [3] shown in Equation (3) has been chosen as underlying implementation model with the assumption that the Arrival Rate of Handoff calls $\left(\lambda_{H}\right)$ is determined by:

$$
\lambda_{H}=\prod(E[c], \mu c-d w e l l)
$$

Where,

$E[c]=$ the average number of calls in a cell

$\mu c-d w e l l=$ the outgoing rate of mobile users

\subsubsection{Determination of E[c]}

For a maximum radial distance $R_{\max }$ (maximum distance from the current $B S$ that provides services its MSs and after the distance an MS forcefully changes from current $B S$ to another $B S$ ) from the underlying network, total cells $N$ under a $B S$ is given by:

$$
N=\sum_{r=1}^{R \max }(2 \times r+1)
$$

Average number of MSs we called here as Subscribers(Subs), in any cell $j$ at radial distance $r$ (represented as $\mathrm{Crj}$ in Figure 1) is obtained by Equation (5): 


$$
\text { Subs }=\frac{\text { Total Number of MSs }(\mathrm{S})}{\text { Total Number of Cells }(\mathrm{N})}
$$

Let us consider average number of calls originated by a Sub (MS) is Calls Per Day Per Subscriber (CPD). Thus,

$$
E[c]=\prod(\text { Subs }, C P D)
$$

\subsubsection{Determination of $\mu \mathrm{c}-$ dwell}

Assuming that MSs move any one of the three directions - outwards, inwards and along the same radial level (shown in both Figure 1 and Figure 2), the probability of $M S s$ for simplicity moving outwards is one-third. Since, in every radial distance $r \leq R_{\max }$, there are $2 \times r+1$ cells, thus, average number of calls going outwards (away from the current $B S$ ) for $N$ cells are given by:

$$
\operatorname{Calls}(\uparrow)=\frac{1}{3} \sum_{r=1}^{R \max } \text { Subs } \times C P D \times(2 \times r+1)
$$

Out of the total number of callers (MSs) going out from one radial level to the other, let us assume for the time being again one-third of them come back to the previous radial level. Therefore, total number of calls coming inwards (towards the underlying $B S$ ) is:

$$
\operatorname{Calls}(\downarrow)=\prod(1 / 3, \quad \operatorname{Calls}(\uparrow))
$$

Effective outgoing calls for the base station are therefore obtained by the Equation (9) as:

$$
\text { Effective Calls }(\uparrow)=\text { Calls }(\uparrow)-\operatorname{Calls}(\downarrow)
$$

Now, for Equation (3) we can compute the outgoing rate of mobile users' $\mu c-d w e l l$ and it is given by:

$$
\mu c-d w e l l=\frac{\text { Effective } \operatorname{Calls}(\uparrow)}{\text { Total Number of Cells }(\mathrm{N})}
$$

\subsection{Priority Handoff Scheme}

An MS approaches cells from a cell with significant signal strength as priority set to Handoff requests by assigning channels $S_{R}$ exclusively for Handoff calls out of $S$ channels. Both originating calls and Handoff requests share the remaining $S_{C}=S-S_{R}$ channels. The blocking probabilities, $B_{O}$ for an originating call, and $B_{H}$ of a Handoff request have been determined by Equations 1.22, and 1.23 in [3] with the steady-state probabilities $P(0)$ and $P(i)$ at states " 0 " and " $i$ " as expressed in Equations. 1.20, and 1.21 in [3] respectively.

\subsection{Determination of Call Blocking Rate}

An MS when initiates a call generally expects to be serviced and enqueued in priority queue. Afterward a call gets serviced by its current MT taking advantage of Splay operations [16][23] on the Splay Tree [23] implementation of the priority queue followed by selection of the call from the tree using SIRO [16][17] queuing principle for providing service. At particular level $r, 1 \leq r \leq R_{\max }$ number of calls blocked i.e. Call Blocking Rate $\left(C B R_{r}\right)$ can be decided by the Equation (11). This blocking does not mean discard of calls rather number calls gets serviced.

$$
C B R_{r}=\frac{1}{3} \prod\left(R_{C_{j r}}, \quad B_{O},(2 \times r+1)\right)
$$

It is generally expected to be $90-100 \%$ so that the Call Dropping Rate $\left(C D R_{r}\right)$ at a $r \leq R_{\max }$ [1][8] is minimum as much as possible.

\section{Numerical Results}

The parameters used for simulation are commonly used to analyze Handoff performance. Simulation of the suggested model has been performed in MATLAB Version 7.6.0.324 (R2008A). Numerical values of the fundamental parameters for Handoff initiation, arrival rate $\lambda_{O}$, and the departure rate $\mu$ are based on COAI Report [24][25] for our beloved Megacity Kolkata. And they are set as $\lambda_{O}=1991$, and $\mu=2212$ [13]. Exploiting these numerical values and inheriting necessary data from [16], all the Equations (3) through (10) and section 2.4 in this paper we have shown two observations.

\subsection{Observation I}

Let us suppose that a mobile station makes at least 5 requests per day. Other values are shown in Table II. Graphical views of the Table II and followed by it, have been shown for the parameters $\lambda_{H}, B_{O}$, and $B_{H}$ with varying radius (radial) distance in Figures 3 to 5 respectively. 
Table II: Performance Metrics for Different Parameters at Radial Levels

\begin{tabular}{|c|c|c|c|c|c|c|c|c|}
\hline Parameters & $\begin{array}{c}\text { Outgoing } \\
\text { Calls }\end{array}$ & $\begin{array}{c}\text { Incoming } \\
\text { Calls }\end{array}$ & $\begin{array}{c}\text { Effective } \\
\text { Calls }\end{array}$ & $\mu_{\mathrm{c}}$ & $\lambda_{\mathrm{o}}$ & $\mu$ & $\mathrm{P}(0)$ & Average $\mathrm{B}_{\mathrm{o}}$ \\
\hline & 221.249 & 73.749 & 147.499 & 0.6584 & 22.885 & 25.427 & 0.2363 & 0.7636 \\
& & & & & & & & \\
\hline$\lambda_{\mathrm{h}}$ & 29.26776 & 48.77959 & 68.29143 & 87.80327 & 107.3151 & 126.8269 & 146.3388 & 165.8506 \\
& 185.3625 & 204.8743 & 224.3861 & 243.898 & 263.4098 & 282.9216 & \\
\hline Bo & 0.25456 & 0.40729 & 0.51639 & 0.60124 & 0.67066 & 0.72941 & 0.78032 \\
& 0.82524 & 0.86543 & 0.9018 & 0.935 & 0.96555 & 0.99383 & 1.0202 \\
\hline$B_{h}$ & 0.092985 & 0.12777 & 0.16256 & 0.19735 & 0.23214 & 0.26693 & 0.30172 \\
& 0.3365 & 0.37129 & 0.40608 & 0.44087 & 0.47566 & 0.51045 & 0.54524 \\
\hline
\end{tabular}

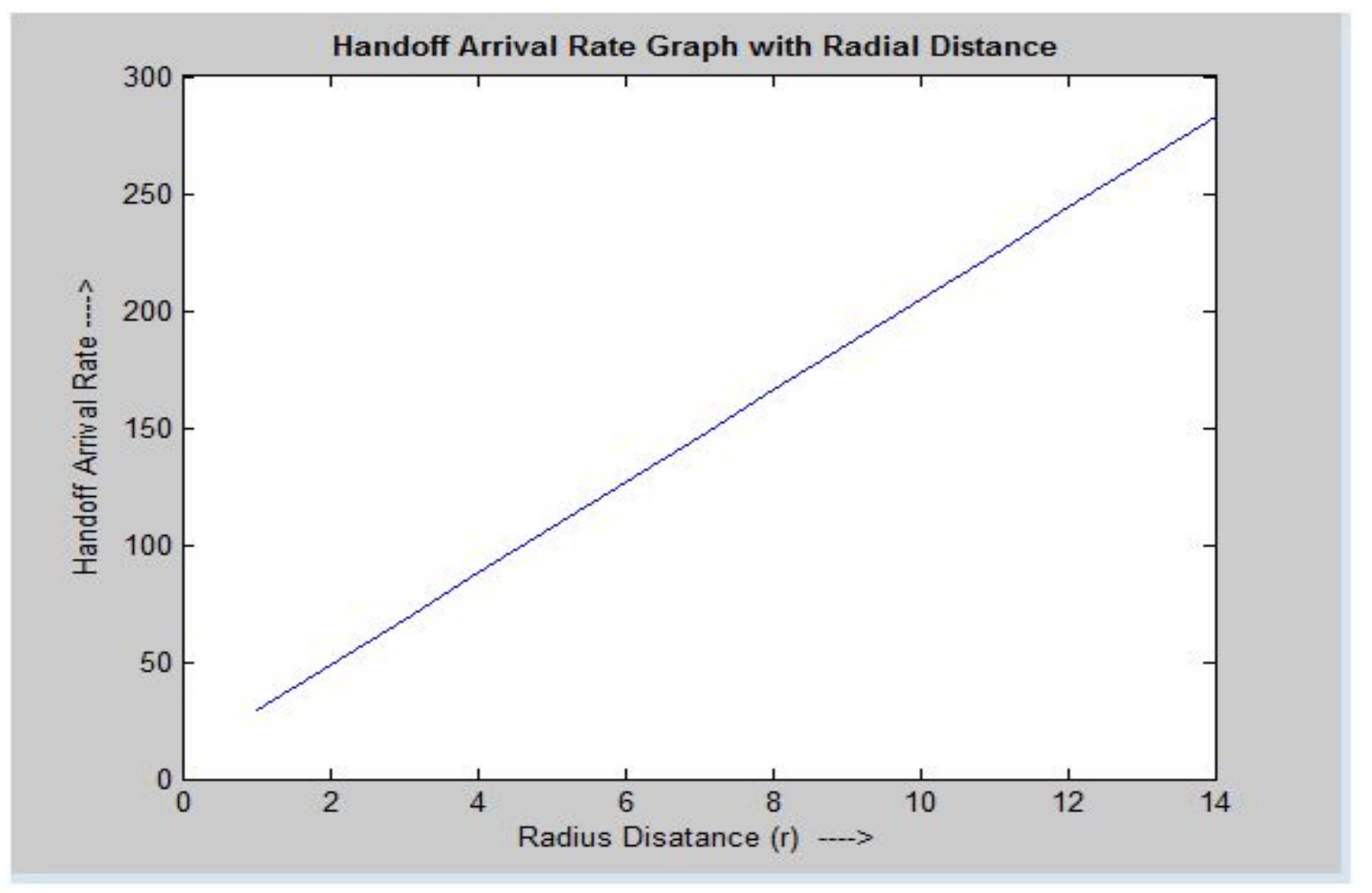

Figure 3. Handoff Arrival Rate vs. Radial Distance 


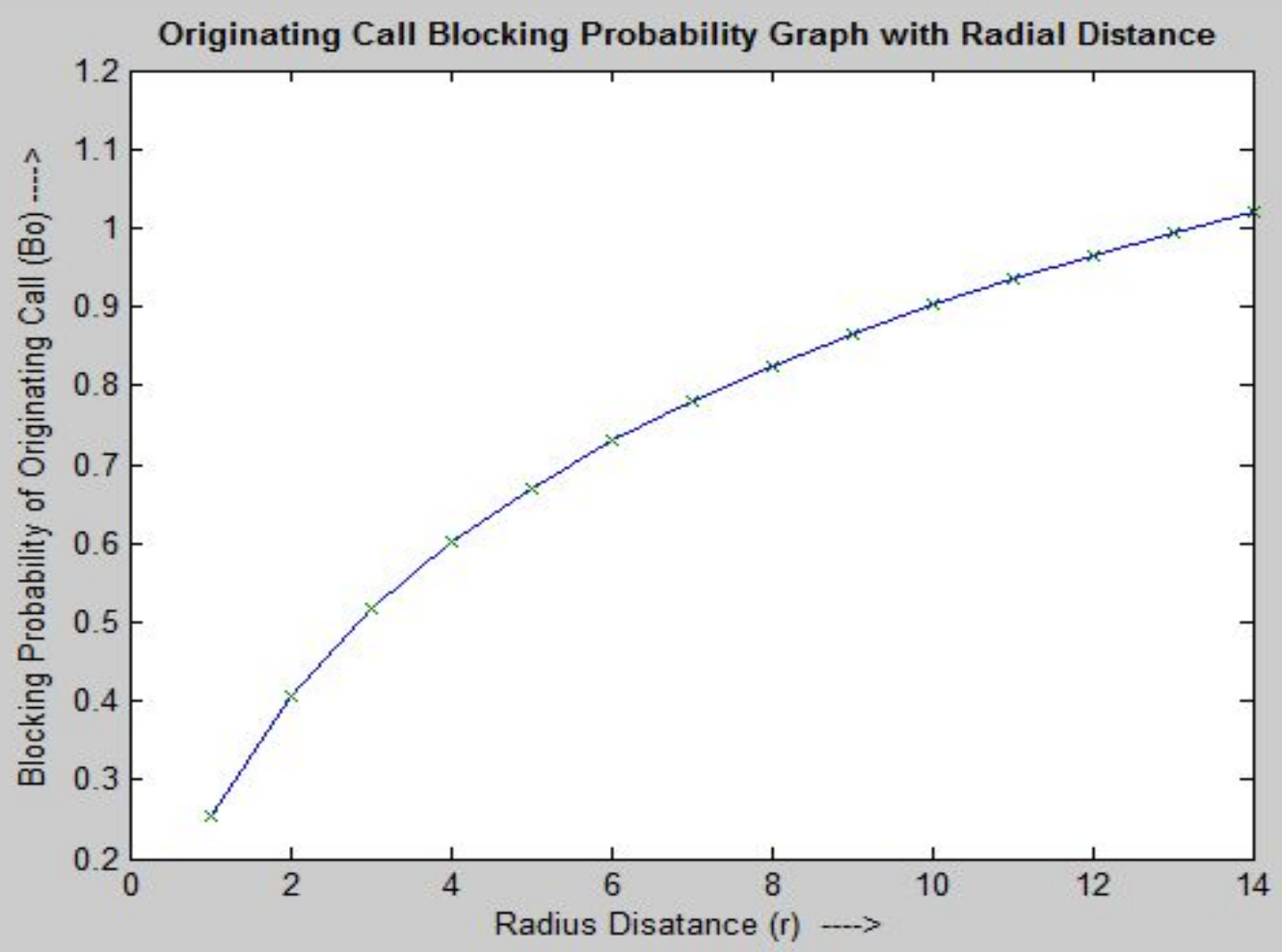

Figure 4. Blocking Probability of Originating Call vs. Radial Distance

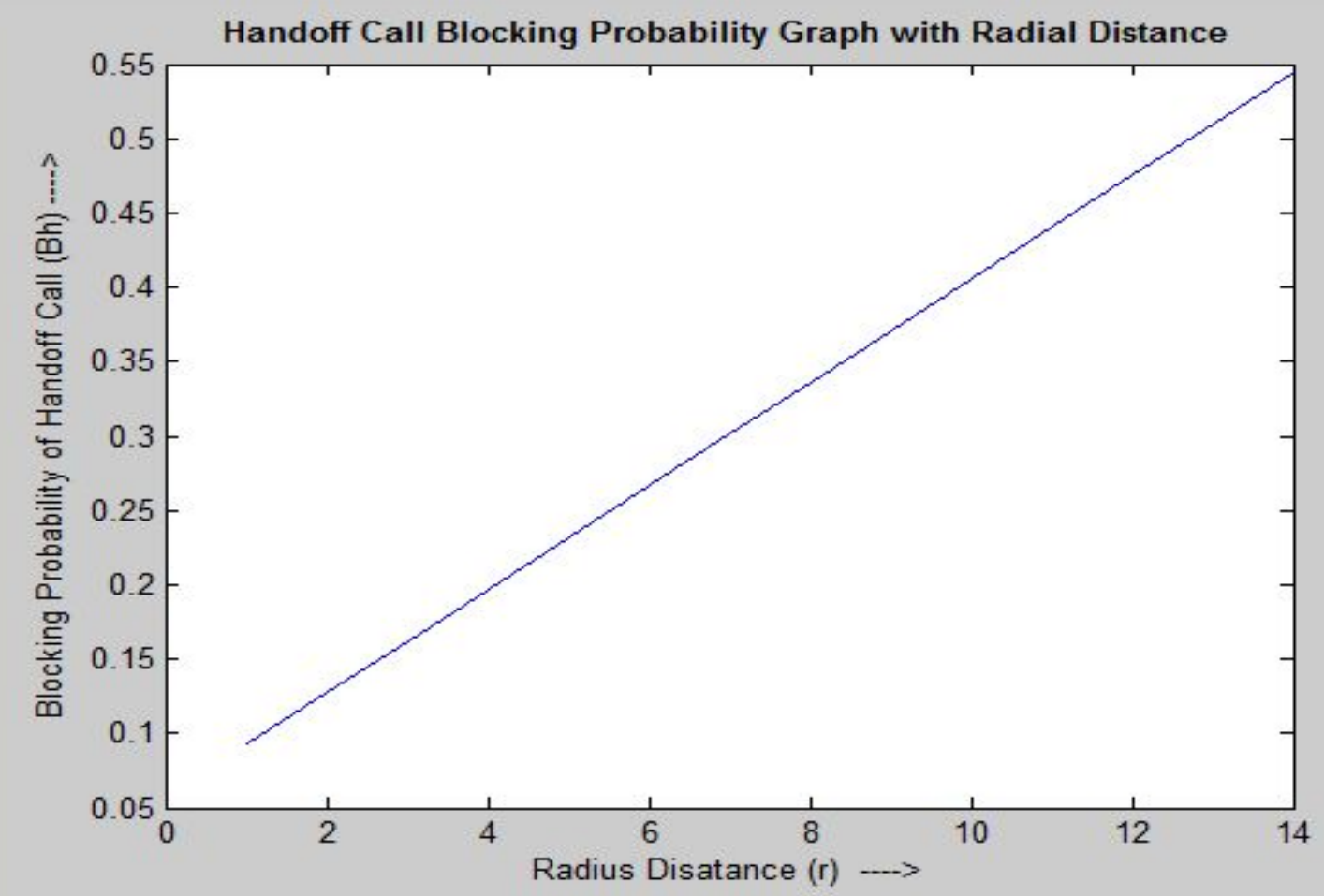

Figure 5. Blocking Probability of Handoff Call vs. Radial Distance

\subsection{Observation II}

Let us suppose that a mobile station makes at least 6 requests per day. Other values are shown in Table III. Similarly graphical views of the Table III and followed by it, have been shown for the parameters $\lambda_{H}, B_{O}$, and $B_{H}$ with varying radius (radial) distance in Figures 6 to 8 respectively. 
Table III: Performance Metrics for Different Parameters at Radial Levels

\begin{tabular}{|c|c|c|c|c|c|c|c|c|}
\hline Parameters & $\begin{array}{c}\text { Outgoing } \\
\text { Calls }\end{array}$ & $\begin{array}{c}\text { Incoming } \\
\text { Calls }\end{array}$ & $\begin{array}{c}\text { Effective } \\
\text { Calls }\end{array}$ & $\mu_{\mathrm{c}}$ & $\lambda_{\mathrm{o}}$ & $\mu$ & $\mathrm{P}(0)$ & $\begin{array}{c}\text { Average } \\
\mathrm{B}_{\mathrm{o}}\end{array}$ \\
\hline & 221.2494 & 73.7498 & 147.4996 & 0.8779 & 26.546 & 29.496 & 0.1662 & 0.833 \\
\hline$\lambda_{\mathrm{h}}$ & 52.03157 & 86.71928 & 121.407 & 156.0947 & 190.7824 & 225.4701 & 260.1578 \\
& 294.8455 & 329.5332 & 364.221 & 398.9087 & 433.5964 & & \\
\hline Bo & 0.2779 & 0.44465 & 0.56375 & 0.65638 & 0.73217 & 0.79631 & 0.85189 & 0.90093 \\
& 0.94481 & 0.98451 & 1.0208 & 1.0541 & & \\
\hline$B_{h}$ & 0.18773 & 0.24523 & 0.30272 & 0.36021 & 0.41771 & 0.4752 & 0.53269 \\
& 0.59019 & 0.64768 & 0.70517 & 0.76267 & & & \\
\hline
\end{tabular}

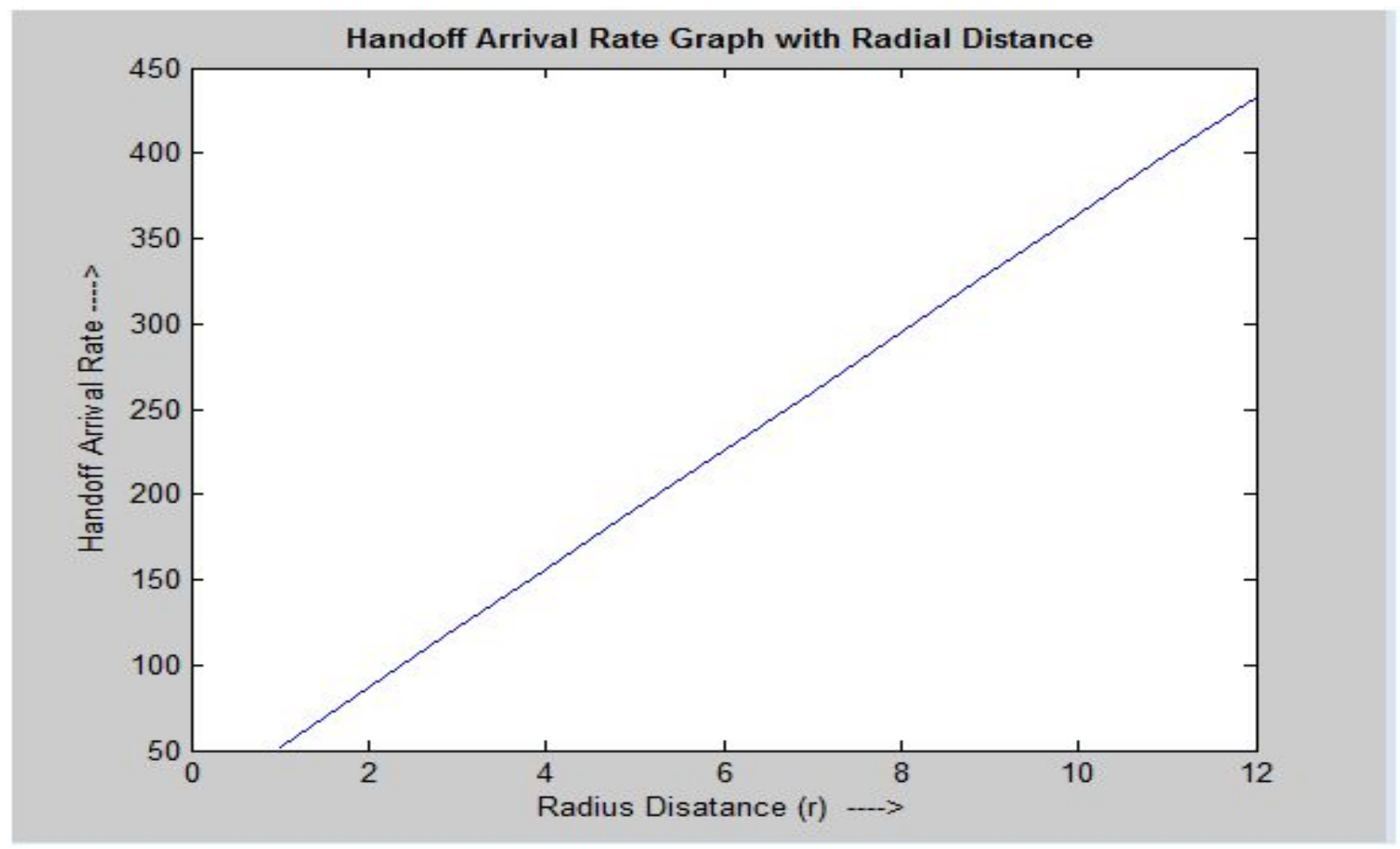

Figure 6. Handoff Arrival Rate vs. Radial Distance 


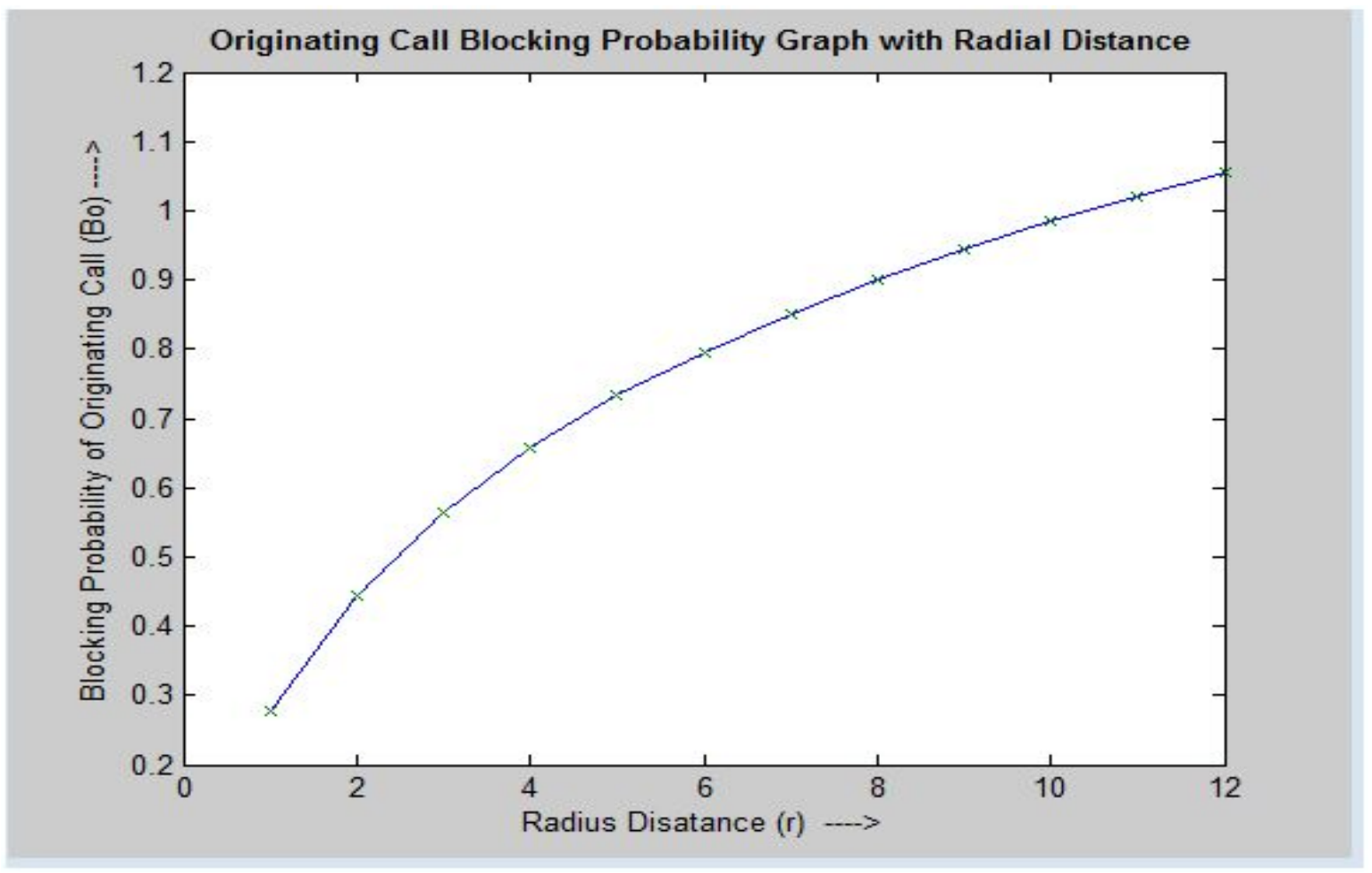

Figure 7. Blocking Probability of Originating Call vs. Radial Distance

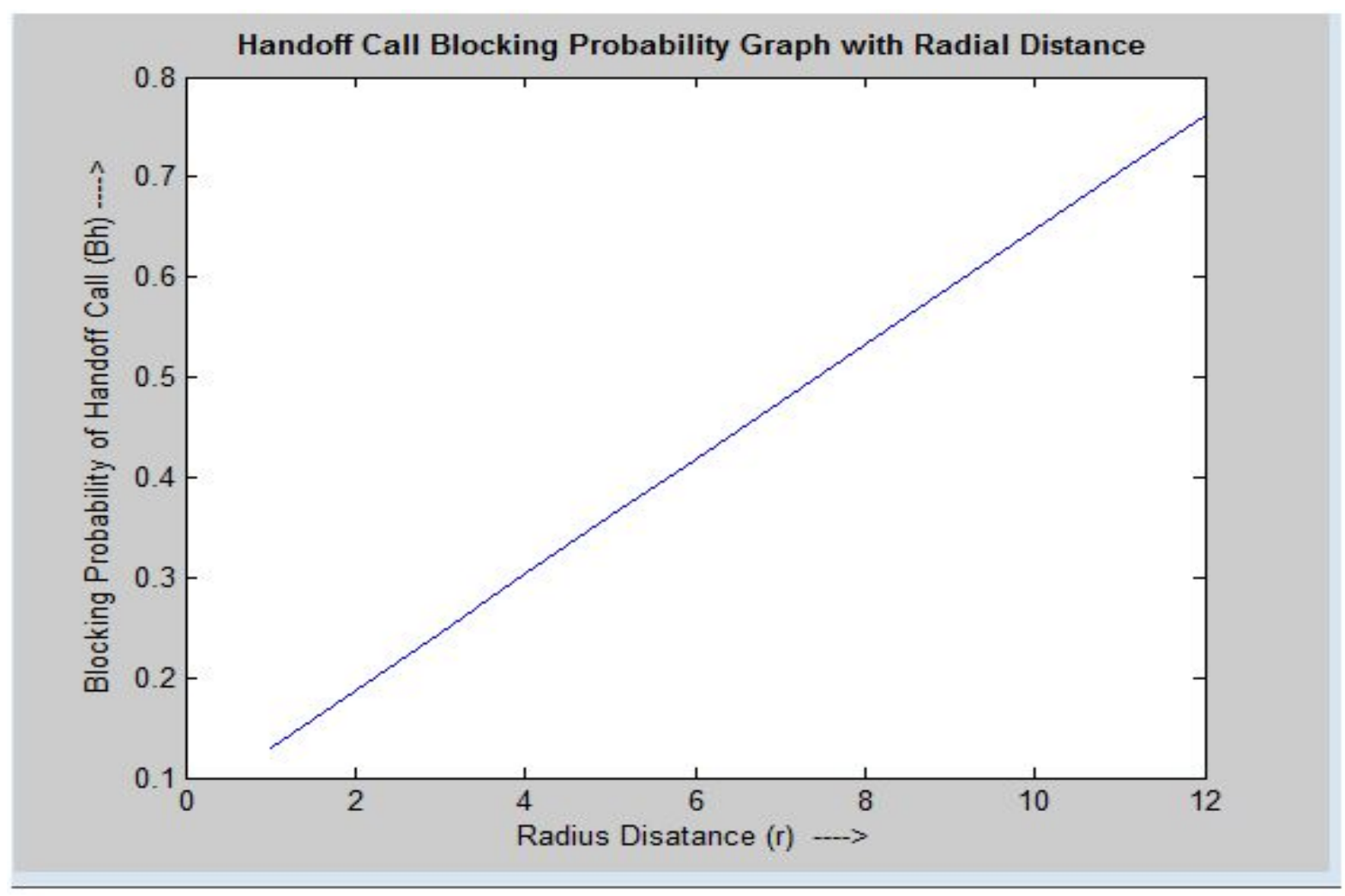

Figure 8. Blocking Probability of Handoff Call vs. Radial Distance

\section{Concluding Remarks}

In this paper we claim that simulated results guarantee that our approach or the model described performs better like some existing algorithms for Handoff scheme. It is observed that increasing average number of calls per 
mobile station per day helps in improvement of the blocking probabilities for both originating calls and Handoff request calls. And these values are nearer to their actual values. Another achievement of the proposed model is working out of rate of blocked calls $C B R$, in addition. Although its behavior is not shown in this paper but similar job has been done in [1][8]. Simulation shows that $C B R$ is increasing in nature with the increase in certain radial distance. After that increases slowly and saturates at $r=R_{\max }$. Surprisingly at $r>R_{\max }$ it is decreasing in nature. It shows that a Handoff just occurred.

However, exact analytical models are difficult to define for the schemes, and if data traffic also needs to be incorporated, it becomes very difficult to have even an approximate model. This is an interesting topic that calls for further research.

\section{Acknowledgements}

The first author would like to express heartily gratitude to Dr. S. V. Rao, Associate Professor, Dr. S. Ranbir Singh, Assistant Professor, Department of Computer Science \& Engineering, Indian Institute of Technology Guwahati, and Mr. P. K. Guhathakurta, Assistant Professor, Department of Computer Science \& Engineering, National Institute of Technology Durgapur for their valuable suggestions, remarks, criticisms, and comments towards quality improvement of this paper. Other authors would also like to express their thankfulness to their friends specially classmates at Department of Computer Science \& Engineering, Bengal College of Engineering and Technology, Durgapur for their dear inspirations and moral supports.

\section{References}

[1] Biswajit Bhowmik, Arnab Sarkar, Parag Kumar Guha Thakurta, Simulation of Handoff Management Scheme for Improved Priority Based Call Scheduling with a Single Traffic System in Mobile Network, Int. J. of Advanced Research in Computer Science, Volume 1, Number 3, 2010, Pp: $354-358$.

[2] N. Mohan, T. Ravichandran, An Efficient Multiclass Call Admission Control and Adaptive Scheduling for WCDMA Wireless Network, European Journal of Scientific Research, Volume 33, Number 4, 2009, Pp:718 $-727$.

[3] Qing-an Zeng and Dharma P. Agrawal, Handbook of Wireless Networks and Mobile Computing, John Wiley \& Sons, Chapter 1, 2002.

[4] Alexe E. Leu, Brian L. Mark, A Discrete-Time Approach to Analyze Hard Handoff Performance in Cellular Networks, IEEE Transactions on Wireless Communications, Volume 3, Number 5, 2004, Pp: 1721 -1733 .
[5] S. A. Mawjoud, Simulation of Handoff Techniques in Mobile Cellular Networks, Al-Rafidain Engineering, Volume 15, Number 4, 2007, Pp: 31 - 39.

[6] Huamin Zhu and Kyung Sup Kwak, An Adaptive Hard Handoff Algorithm for Mobile Cellular Communication Systems, ETRI Journal, Volume 28, Number 5, October 2006, Pp: 676 - 679.

[7] Biswajit Bhowmik, Pooja, Piyali Sarkar, Nupur Thakur, Experimental Analysis of Single Traffic Priority Handoff Management Scheme and Signal Strength Based Effective Call Scheduling in Wireless Mobile Networks, Final Year Project Report, https://sites.google.com/site/biswajitrbhowmik/academic s/projects.

[8] Biswajit Bhowmik, Smita Roy, Parag Kumar Guha Thakurta, Arnab Sarkar, Priority Based Hard Handoff Management Scheme for Minimizing Congestion Control in Single Traffic Wireless Mobile Networks, International Journal of Advancements in Technology, Volume 2(1), 2011, Pp: 90 - 99.

[9] Zhenqiang Ye et al, Predictive channel reservation for handoff prioritization in wireless cellular networks, Elsevier, Computer Networks, 51 (2007), Pp: 798 - 822.

[10] Kishor S. Trivedi, S. Dharmaraja 1, Xiaomin Ma, Analytic modeling of handoffs in wireless cellular networks, Elsevier, Information Sciences 148 (2002), Pp: 155-166

[11] P. K. Guha Thakurta, Souvik Sonar, Biswajit Bhowmik, Swapan Bhattacharya, Subhansu Bandyopadhyay, A New Approach on Priority Queue based Scheduling with Handoff Management for Mobile Networks, SEDE, ISCA, 2010, Pp: $69-74$.

[12] P. K. Guha Thakurta, Subhansu Bandyopadhyay, A New Dynamic Pricing Scheme with Priority based Tree Generation and Scheduling for Mobile Networks, IEEE Xplore, 2009.

[13] Jo“rg Diedericha, Martina Zitterbart, A simple and scalable handoff prioritization scheme, Elsevier, Computer Communications 28 (2005), Pp: 773-789.

[14] Jinfang Zhang, Jon W. Mark, Xuemin (Sherman) Shen,An adaptive handoff priority scheme for wireless MC-CDMA cellular networks supporting realtime multimedia applications, Elsevier, Computer Communications 28 (2005), Pp: 1240-1250.

[15] O* Zgu“ R. B. Akan And Buyurman Baykal, Handoff Performance Improvement with Latency Reduction in Next GenerationWireless Networks, Springer, Wireless Networks 11, 2005, Pp: 319-332.

[16] Biswajit Bhowmik, Pooja, Piyali Sarkar, Nupur Thakur, Received Signal Strength Based Effective Call Scheduling in Wireless Mobile Network, International Journal of Advancements in Technology, Volume 2, Number 2, 2011, Pp: $292-305$. 
[17] J K Sharma, Operations Research - Theory and Application, Macmillan Publishers, 3/e, 2006.

[18] S. A. Mawjoud, Simulation of Handoff Techniques in Mobile Cellular Networks, Al-Rafidain Engineering, Volume 15, Number 4, 2007, Pp: 31 - 39.

[19] Raymond M. Bendett and Perambur S. Neelakanta, Alternative Metrics for Hard Handoffs in Mobile Communication, ICPWC 2000, IEEE, 2000, Pp: 43 - 46. [20] Polychronis Koutsakis , Moisis Vafiadis , Aggelos Lazaris, A new bandwidth allocation mechanism for next generation wireless cellular networks, Springer, Wireless Netw, Volume 16, 2010, Pp: 331-353.

[21] CUI Hong-yan, TIAN Hui, XU Hai-bo, ZHANG Ping, The Research on Handoff Strategy in Beyond 3G Wireless Networks, The Journal Of China Universities Of Posts And Telecommunications Volume 13. Number 2, 2006.

[22] Vassilya Abdulova, Isik Aybay, Predictive mobile-oriented channel reservation schemes in wireless cellular networks, Springer, Wireless Netw Volume 17, 2011, Pp: 149-166.

[23] Thomas H. Cormen, Charles E. Leiserson, Ronald L. Rivest, and Clifford Stein, Introduction to Algorithms, PHI, 2nd Edition, 2006.

[24] http://www.coai.com/study_papers.php?val=2010.

[25] http://en.wikipedia.org/wiki/Kolkata\#Geography.

${ }^{1}$ Biswajit Bhowmik is currently doing $\mathrm{PhD}$ in the Department of Computer Science \& Engineering of Indian Institute of Technology Guwahati. He was a very renowned faculty member with Bengal College of Engineering and Technology, Durgapur, India as Assistant Professor in the Department of Computer Science \& Engineering for almost 7 years. $\mathrm{He}$ is a member of different professional bodies such as IEEE, IACSIT, IAENG, PASS, IAOE, UACEE, etc. He is also member of IEEE Computer Society, IAENG Society of Computer Science, IAENG Society of Wireless Networks, IAENG Society of Software Engineering, and IAENG Society of Artificial Intelligence. He is reviewer of several international journals such as IJCSIC, IJCSIS, JACSM, IJoAT, JWMC, etc in the area of computer science. He has authored a book titled Design and Analysis of Algorithms. He has many publications in international journals including international conference proceedings on the subjects ranging from Algorithms Analysis, Graph Theory, Mobile Computing, Data Structures \& Algorithms, Computational Geometry, and Green Computing. He has guided several projects at under graduate level. This paper is based on Mobile Computing as Final Year Thesis Work done by the co-authors for UG Curriculum under West Bengal University of Technology, Kolkata, India.

${ }^{2}$ Pooja, Nupur Thakur, and Piyali Sarkar are Final Year UG (B.Tech) students in the Department of Computer Science \& Engineering of Bengal College of Engineering and Technology, Durgapur, India. 